\title{
The Effects of Licorice (Glycyrrhriza glabra) Root on Performance, Some Serum Parameters and Antioxidant Capacity of Laying Hens
}

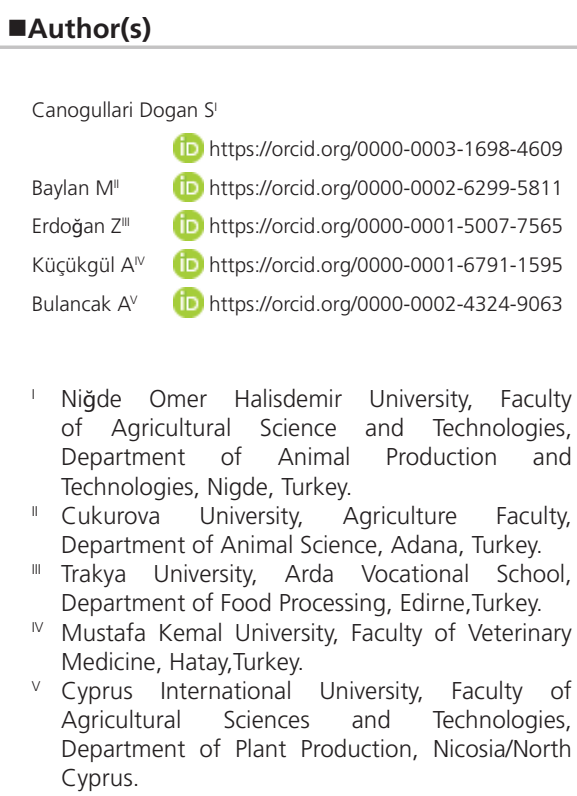

\section{Mail Address}

Corresponding author e-mail address Sibel Canogullari Dogan

Niğde Omer Halisdemir University, Faculty of Agricultural Science and Technologies, Department of Animal Production and Technologies, Nigde, 51240, Turkey. Phone: +903882254458

Email: sibelcanogullari@gmail.com

\section{-Keywords}

Antioxidant capacity, egg cholesterol, Glycyrrhriza glabra, laying hen, performance, some plasma parameters.

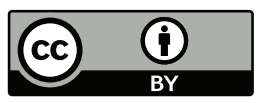

Submitted: 01/March/2018 Approved: 18/June/2018

\section{ABSTRACT}

The current study was conducted to determine the effects of the licorice root (Glycyrrhriza glabra) in laying hens diets on performance, egg cholesterol, some plasma parameters and antioxidant capacity. One hundred, 40-week old laying hens were divided into four groups, each group consisted of 25 hens and were placed in individual cages. The mean of the initial body weight of laying hens was $1829.18 \pm 9.595$ g. Commercial laying hen diet was supplemented with 0, 0.5, 1.0 and $2.0 \%$ levels of licorice root powder and four different dietary groups were formed. From the experimental findings, it was ascertained that the licorice root supplementation had no significant effect on egg weight and feed conversion ratio $(p>0.05)$, but feed consumption decreased with increasing licorice root $(p<0.05)$. Egg yield was recorded as $88.94 \%, 89.56 \%, 86.82 \%$ and $85.02 \%$ in the groups of $0,0.5$, 1.0 and 2.0 , respectively $(p<0.05)$. Plasma low density lipoprotein (LDL) and egg yolk cholesterol level decreased with the addition of licorice root, while plasma high density lipoprotein (HDL) level was increased with licorice root addition $(p<0.05)$. Licorice root addition had a positive effect on total antioxidant capacity (TAS) of plasma. It was determined that the total antioxidant capacity was increased by increasing amount of licorice root.

From the overall findings, it can be concluded that licorice root could be used as a feed additive without any adverse effect on performance. It has been demonstrated that the licorice root enables the production of functional eggs.

\section{INTRODUCTION}

Over the centuries, due to having various pharmacological effects, many natural medicinal and aromatic plants are being used as medicine and spices. Enriched with several bioactive compounds, these plants are also an abundant source of various functional properties (Kohlert et al., 2000). Plants and their extracts are consumed by humans and animals regarded as health-friendly and safe additives in terms of chemical structure. However, from the study of literatures regarding the application of these plants in animal nutrition up to 2006, it can be found that, the implementation of these plants as food additives has increased after the prohibition of antibiotics.

Licorice root (Glycyrrhriza glabra) is among the oldest and most widely known medicinal plants throughout the world. Although licorice plant has been used for many years in traditional herbal medicine, compounds and pharmacological effects have been revealed in recent scientific research conducted over the last 25-30 years (Asl \& Hosseinzadeh, 2008). Huge amounts of pharmacologically active compounds have been isolated from licorice plant and have been identified and verified by modern analytical techniques. The majority of these bioactive 
Canogullari Dogan S, Baylan M, Erdoğan Z, Küçükgül A, Bulancak A
The Effects of Licorice (Glycyrrhriza glabra) Root on Performance, Some Serum Parameters and Antioxidant Capacity of Laying Hens compounds are form triterpene saponins (4-20\%) and various types of phenolic compounds (Fiore et al., 2008; Tan et al., 2010).

It has been reported that glabridin has the strong antioxidant activity from the main isoflavonoid compounds of the plant (Shibata, 2000). Ju (1989) has shown that the antioxidant effect of licorice flavonoids is 100-fold greater than that of E vitamin. Glycyrrhizin and glycyrrhizinic acid, the main compounds of the triterpen saponins, are mainly antioxidant (Ju 1989; Vaya et al., 1997; Doğan, 2004), anti-inflammatory (Yokota et al., 1998) anti-ulcer (Aly et al., 2005), antiviral (Utsunomiya et al., 1997; Fiore et al., 2008), antiallergic, anticarcinogenic and immunomodulatory effects have been demonstrated as a result of clinical and experimental studies (Shibata, 2000; Asl \& Hosseinzadeh, 2008).Other important effects of glycyrrhizin and glycyrrhizinic acid have been reported to have cardioprotective, hepatoprotective and plasma lipid-lowering effects (Fuhrman et al., 2002, Nakagawa et al., 2004, Visavadiya \& Narasimhacharya, 2006).

Studies on the effects of triterpenoid saponins and flavonoid compounds possessed by licorice root on human and experimental animals have been intensified in recent years. Visavadiya \& Narasimhacharya (2006) stated that significant decreases in plasma total hepatic lipid, cholesterol, triglyceride, and plasma LDL and VLDL in rabbits supplemented with 5 and $10 \%$ Glycyrrhiza glabra root in their diets were observed, while they reported an increase in HDL-cholesterol content. In the same study, licorice root was reported to improve hepatic HMG-CoA reductase activity, prevent lipid peroxidation by increasing the amount of superoxide dismutase (SOD) and catalase enzyme.

Nitalikar et al. (2010) investigated the antimicrobial activity of licorice root extracts and reported that it has a significant effect on gram positive (Bacillus subtili and Stapphylococcus aureus) and gram negative (Escherichia coli and Pseudomonas aeruginosa) bacteria. Sen et al. (2011) reported that glycyrrhizin, one of the key compounds of the licorice root normalized Superoxide dismutase (SOD) and catalased activity and Malondialdehyde (MDA) levels which are oxidative stress parameters in diabetic rats. Karami et al. (2013) reported that the licorice root was also effective on gram positive and gram negative bacteria such as Salmonella enteritidis (gr-), Escherichia coli (gr-), Bacillus cereus ( $\mathrm{gr}+$ ) and Staphylococcus aureus $(\mathrm{gr}+)$. The studies conducted using licorice root was carried out especially with broiler chickens, but limited number of studies were found for the effect of it on laying hens.
For this purpose, in the present study, the effects of bioactive compounds contained in the licorice plant were investigated on the performance and on some plasma lipid profile of lipid metabolism in terms $\mathrm{HDL}$, $\mathrm{LDL}$, total cholesterol and total triglyceride levels of laying hens. In addition, the effects of the plant on antioxidant status of the hens were revealed with total antioxidant and oxidant status (TAS and TOS) parameters. At the same time, the effect of licorice to the cholesterol content of the eggs was also determined.

\section{MATERIAL AND METHODS}

\section{Animal and Feed Material}

A total of 100 Lohman Brown laying hens at 40 week of age with an initial body weight range between 1828.50 to $1830.20 \mathrm{~g}$ were obtained from research and application farm poultry unit, Faculty of Agriculture, Çukurova University, Turkey (latitude is 36.976 and longitude is 35.4535). The hens were weighed individually and divided into four groups of 25 hens each and housed individually in $55 \mathrm{~cm} \times 50 \mathrm{~cm} \times 45 \mathrm{~cm}$ battery cages equipped with nipple drinkers. Corn and soybean based commercial diet containing $2700 \mathrm{kcal} / \mathrm{kg} \mathrm{ME}$ and $16 \%$ crude protein was used as feed material for the laying hens. The basic ingredient and chemical composition of commercial diet is shown in Table 1. Commercial laying hen diet was supplemented with $0,0.5,1.0$ and $2.0 \%$ levels of licorice root powder and four different dietary groups were formed. Licorice root was obtained from Hatay province which is situated in southern Turkey, on the eastern Mediterranean coast. The latitude of Hatay is 36.3524, and the longitude is 36.2935 .

The experiment lasted 8 weeks. During the experiment, all hens were housed in an environment with 16 hours of light and 8 hours of darkness, temperature of $21^{\circ} \mathrm{C}$, ambient humidity of $50-60 \%$ and feed-water were given ad-libitum. All protocols for the experiment were reviewed and approved by the local animal care and use committee of Çukurova University (30.10.2014/7)

\section{Productive Performance}

During the study, feeds were given daily to hens in individual cages and weekly feed consumption was calculated by taking advantage of daily feed consumption. The individual weekly feed consumption was divided by the individual weekly egg weight, and the individual feed conversion ratio was calculated. 
The Effects of Licorice (Glycyrrhriza glabra) Root on Performance, Some Serum Parameters and Antioxidant Capacity of Laying Hens
Table 1 - Ingredient and chemical composition of the diet.

\begin{tabular}{|c|c|c|c|}
\hline Ingredient & $\%$ & Calculated Nutrient & Composition \\
\hline Maize & 65.27 & $\mathrm{ME}, \mathrm{kcal} / \mathrm{kg}$ & 2700 \\
\hline Soybean meal & 16.95 & Crude protein, \% & 16.00 \\
\hline Sunflower meal & 3.70 & Crude fiber, \% & 3.90 \\
\hline Fish meal & 3.00 & Crude fat, \% & 4.67 \\
\hline Dicalcium phosphate & 1.2 & Calcium, \% & 4.00 \\
\hline Marble powder & 8.98 & Available phosphorus, \% & 0.52 \\
\hline Salt & 0.20 & Methionine, \% & 0.30 \\
\hline Vitamin premix* & 0.10 & Methionine \& Cysteine, \% & 0.61 \\
\hline Mineral premix** & 0.10 & Lysine, \% & 0.68 \\
\hline DL-Methionine & 0.50 & Sodium, \% & 0.16 \\
\hline \multicolumn{4}{|l|}{100.00} \\
\hline \multicolumn{4}{|c|}{ 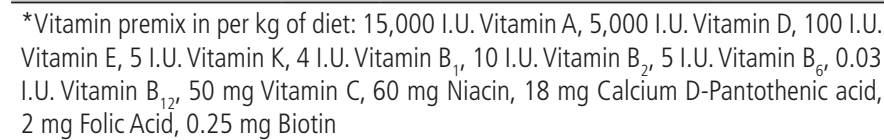 } \\
\hline \multicolumn{4}{|c|}{$\begin{array}{l}\text { ** Mineral premix in per } \mathrm{kg} \text { of diet: } 100 \mathrm{mg} \text { Manganese, } 80 \mathrm{mg} \text { Iron, } 100 \mathrm{mg} \text { Zinc, } 10 \\
\mathrm{mg} \text { Copper, } 0.2 \mathrm{mg} \text { Cobalt, } 1.5 \mathrm{mg} \text { lodine, } 0.2 \mathrm{mg} \text { Selenium. }\end{array}$} \\
\hline
\end{tabular}

Feed Conversion Ratio= Individual feed consumption (g/week) /Individual egg weight (g/week)

During the experiment, eggs were collected daily from the cage and weighed with a scale of $0.01 \mathrm{~g}$. Egg yields were calculated by recording the number of eggs collected daily.

Egg yield (hen day) \% = (number of eggs (week) / number of chickens) $* 100$

\section{Egg Yolk Cholesterol}

At the $4^{\text {th }}$ and $8^{\text {th }}$ weeks of the experiment, egg yolk cholesterol levels were analyzed by collecting 15 eggs from each experimental group. For this purpose, the egg samples were boiled until the egg yolk solidified, then were transferred to the tubes by taking samples from the boiled egg yolk and stored at $-80{ }^{\circ} \mathrm{C}$ until analysis. Fat extraction from samples was performed according to the method developed by Boselli et al. (2010). According to this method egg yolk samples were added in a 2: 1 ratio of 30/70 ethanol / chloroform solution and stirred for $30 \mathrm{~min}$ at $21^{\circ} \mathrm{C}$. The solution obtained at the end of the period was filtered clean tube by vacuum filtration method. Egg yolk cholesterol levels were estimated by spectrophotometric method using the Boehringer Manheim GmbhBiochemica (1989).

\section{Biochemical Analysis}

To determine the effect of licorice root on some plasma parameters and antioxidant capacity, eight randomly selected animals from each group were chosen at the end of the experiment and blood samples were taken from the brachial wing vein. Blood samples were placedin EDTA anticoagulant tubes and centrifuged for 10 minutes at $3000 \mathrm{rpm}$ to separate plasma from whole blood. Plasma samples were kept at $-80^{\circ} \mathrm{C}$ until analyzed. Plasma glucose levels and plasma lipid profiles (HDL, LDL, total cholesterol, total triglyceride) of the samples were tested spectrophotometrically according to the protocols of commercial kits (Erba Mannheim, CZ).

\section{Total Antioxidant and Oxidant Status, Oxidative Stress Index}

At the end of the study, total antioxidant and oxidant status (TAS and TOS) parameters were detected in plasma samples taken from eight randomly selected animals from each group. TAS and TOS levels were determined by spectrophotometer following the methodology of commercial kits (Rel Assay, Diagnostics).

The effect of licorice root on oxidant stress and the antioxidant system were determined by oxidative stress index by measuring the total antioxidant and oxidant status (TAS and TOS) parameters. The oxidative stress index is equal to the percentage of total oxidant status to total antioxidant status. The TAS value obtained in the study as mmol / $L$ was converted to $\mu \mathrm{mol} / \mathrm{L}$ and the oxidative stress index was calculated according to the following formula (Kosecik et al., 2005).

OSI $=\left[\mathrm{TOS}, \mu \mathrm{mol} \mathrm{H}_{2} \mathrm{O}_{2}\right.$ equiv./L]/[TAS, $\mu \mathrm{mol}$ Trolox equivalent/L] $\times 100$

\section{Statistical Analysis}

Data obtained in the study were analyzed using the One-way ANOVA procedure of SPSS (SPSS for Windows release 18.0) with Duncan's Multiple Range Test to identify the significant differences between the means.

\section{RESULTS AND DISCUSSION}

The effects of licorice root supplement on performance of laying hens are shown in Table 2 . The body weights at the beginning of the experiment were set to be similar to each other and body weights varied between 1828.50 and $1830.20 \mathrm{~g}$ in the diets groups. However, body weights at the end of the study were reduced with increasing level of licorice root supplement to diets. At the end of the experiment, body weights were determined as 1748.63, 1680.30, 1648.90 and $1635.78 \mathrm{~g}$ in groups containing $0,0.5$, 1.0 and $2.0 \%$ licorice root, respectively. The differences in body weights between the groups were statistically significant $(p=0.086)$ at the end of the experiment. The feed consumption in the groups also decreased with 
Canogullari Dogan S, Baylan M, Erdoğan Z, Küçükgül A, Bulancak A
The Effects of Licorice (Glycyrrhriza glabra) Root on Performance, Some Serum Parameters and Antioxidant Capacity of Laying Hens the addition of licorice root powder at increasing levels in diets $(p=0.001)$. The highest feed consumption was obtained as to be $105.28 \mathrm{~g}$ in the control group and the lowest feed consumption was obtained as 97.47 $\mathrm{g}$ in $2.0 \%$ supplemented group. The decrease in feed consumption with the addition of licorice root between the hens may be due to the aromatic odor of the plant. Indeed, Fiore et al. (2008) have indicated that licorice has a characteristic odor and sweet taste. Rezaei et al. (2014) reported similar results to those obtained in the present study. Researchers investigated the effects of Thymus vulgaris L., Glycyrrhiza glabra, and their mixture and enzyme supplement on broiler performance and they stated that feed consumption and body weight gain were_significantly lower in the Glycyrrhiza glabra supplemented group than in the other groups. Similarly, Amen \& Muhammad (2016) obtained results that showed that the highest body weight was in $1 \mathrm{~g} / \mathrm{kg}$ licorice root extract supplemented group for broiler at the $6^{\text {th }}$ week. They stated that the other licorice root extract on supplemented groups $(1.25$ and $1.5 \mathrm{~g} / \mathrm{kg}$ ) had lower body weight than the control groups. Moradi et al. (2014) reported that body weights of broiler at the end of the experiment (42 days) were 2667.8, 2604.5, 2629.6, 2611.6 $\mathrm{g}$ in $0,0.1,0.2$ and $0.3 \mathrm{mg} /$ lit licorice root extract supplemented to drinking water. They stated that there was no difference between the groups in terms of feed consumption. In this study, final body weight of the licorice root addition group was found to be lower than the control group. Some studies have shown that licorice flavonoids have suppressed body weight by reducing the fat content of the body (Nakagawa et al., 2004; Tominaga et al., 2006). Researchers suggested that the possible mechanism for the reduction of visceral fat and low body weight gain; increase of fatty acid oxidation and reduction of fatty acid biosynthesis.

Unlike the current experiment, Safari \& Zahedi (2016) reported that supplementation of licorice root extract to quail's diets and Salary et al. (2014) reported that the addition of licorice extract to drinking water increased the feed consumption and body weight. Salary et al. (2014) reported that increased consumption of feed could be attributed to a change in the taste of the feed and that this stimulated appetite. Sedgi et al. (2010) stated that Glycyrrhiza glabra added to feeds at a level of $0.5,1$, or $2 \mathrm{~g} / \mathrm{kg}$ had no significant effect on body weight and feed consumption.

In present study, the best feed conversion ratio was obtained from the group of $0.5 \%$ licorice root supplementation and the worst feed conversion ratio from the control group $(p=0.745)$. Safari \& Zahedi (2016) found that the addition of licorice root extract to quail diets, Salary et al. (2014) reported that the addition of licorice extract to drinking water had no effect on the feed conversion ratio. The findings of these researchers are consistent with the results of the present study. Awadein et al. (2010) used 0.1 and $0.5 \%$ licorice root as a source of phytoestrogens in the layer's diets and stated that feed consumption level is lower in 0.1 and $0.5 \%$ licorice root supplemented groups than in the control group. They reported that feed conversion ratio was worse in the control group than in the supplemented groups. Moradi et al. (2014) reported that feed conversion ratio was better in the control group than in the current study $(p>0.05)$.

There was no difference between the groups in terms of egg weight (Table 2) $(p=0.200)$. The highest egg yield was obtained from 0 and $0.5 \%$ licorice root supplemented groups ( $p=0.021$. Similar Results to the present findings also reported by Awadein et al. (2010). Researchers have reported that egg yields were higher in 0.1 and $0.5 \%$ licorice root supplemented group as a source of phytoestrogen than in the control group. In the present study, the highest egg yield was obtained $0.5 \%$ licorice root supplemented group and followed by the control group.

\section{Effects of licorice root on some plasma biochemical parameters and egg yolk cholesterol}

The effects of licorice root supplement on plasma parameters is shown in Table 3. Plasma cholesterol

Table 2 - The effects of licorice root supplementon performance of laying hens*

\begin{tabular}{|c|c|c|c|c|c|}
\hline \multirow{2}{*}{ Parameters } & \multicolumn{4}{|c|}{ Licorice Root Supplementation, (\%) } & \multirow{2}{*}{$p$} \\
\hline & 0 & 0.5 & 1.0 & 2.0 & \\
\hline Initial body weight (g) & $1828.50 \pm 18.774$ & $1829.05 \pm 19.915$ & $1829.00 \pm 18.527$ & $1830.20 \pm 20.946$ & 1.000 \\
\hline Final body weight (g) & $1748.63 \pm 32.978^{a}$ & $1680.30 \pm 40.943^{a b}$ & $1648.90 \pm 27.329^{b}$ & $1635.78 \pm 28.633^{b}$ & 0.086 \\
\hline Feed Consumption (g day hen) & $105.28 \pm 1.464^{a}$ & $103.86 \pm 1.504^{a}$ & $101.25 \pm 1.329^{a b}$ & $97.47 \pm 1.554^{b}$ & 0.001 \\
\hline Feed conversion ratio ( $\mathrm{kg}$ feed/kg egg) & $1.98 \pm 0.029$ & $1.93 \pm 0.032$ & $1.96 \pm 0.036$ & $1.94 \pm 0.037$ & 0.745 \\
\hline Egg weight (g) & $60.42 \pm 0.311$ & $60.77 \pm 0.327$ & $61.16 \pm 0.366$ & $60.26 \pm 0.269$ & 0.200 \\
\hline Egg yield (\%) & $88.94 \pm 1.066^{a}$ & $89.56 \pm 1.041^{a}$ & $86.82 \pm 1.180^{\mathrm{ab}}$ & $85.02 \pm 1.245^{b}$ & 0.021 \\
\hline
\end{tabular}

* The difference between the averages shown in different letters on the same line is significant $(p<0.05)$ 
level was $92.00 \mathrm{mg} / \mathrm{dl}$ in the control group, while it was $86.56,89.43$ and $86.35 \mathrm{mg} / \mathrm{dl}$ in $0.5,1.0$ and $2.0 \%$ in licorice root supplemented groups respectively. There was no statistically significant difference in plasma triglyceride levels among the experimental groups $(p=0.780)$. Although the triglyceride levels of the groups are statistically insignificant, it tended to be lower in licorice added groups than in the control group. While the plasma LDL level decreased with the addition of licorice root $(p=0.071)$, then an increase in HDL level was observed ( $p=0.001)$. In the current study, it was determined that the plasma glucose level increased with the addition of licorice root and this result was in correlation with the findings of $\mathrm{Al}-$ Daraji (2012a) and Al-Daraji (2012b). Al-Daraji (2012a) reported that the addition of $0,150,300$ or $450 \mathrm{mg} / \mathrm{l}$ of licorice root extract to the drinking water in order to investigate the effects of the licorice root extract on broilers, increased plasma glucose level and the cholesterol level decreased $(p<0.05)$. In the present study, it was observed that the plasma cholesterol level decreased with the addition of licorice root. In an earlier study of Al-Daraji (2012b), the effect of 0, 150, 300, $450 \mathrm{mg} / \mathrm{kg}$ licorice root extract supplement to broiler diets was investigated, and it was found that the blood glucose level was increased with increasing levels of licorice root extract. The researchers determined that the cholesterol levels were as 128.2, 134.6, 130.5 and $122.2 \mathrm{mg} / \mathrm{dl}$ in the supplemented groups, respectively and there was a statistically difference between the groups. Sedghi et al. (2010) found that blood glucose levels were higher in the control group in contrast to the results obtained in the current study. The researchers reported that the triglyceride levels were lower in the licorice root supplemented groups compared with the control group, and also stated that the HDL level increased and the LDL level decreased with the licorice root supplementation, but no statistically differences were destined between the groups $(p>0.05)$. They also reported that cholesterol levels were significantly reduced by the addition of licorice root $(p<0.05)$. The results obtained in the study are consistent with the findings of the researchers. Salary et al. (2014) stated that 0.2 and $0.4 \%$ licorice root extract in drinking water of broilers increased blood HDL level $(p<0.05)$, and the cholesterol levels were 115.66, 123.66 and 106 $\mathrm{mg} / \mathrm{dl}$ in the $0,0.2$ and $0.4 \%$ supplemented groups, respectively. They stated that triglyceride and LDL levels increased with the addition of licorice root, unlike the existing findings. Visavadiya \& Narasimhacharya (2006) have reported a significant decrease in plasma hepatic lipid, cholesterol, triglycerides, LDL and VLDL levels while the increase in HDL-cholesterol content. Sharifi et al. (2013) reported that it may be due to the inhibition of hepatic 3-hydroxy-3-methylglutarylcoenzyme A (HMG-COA), an enzyme active at plasma HDL levels. Sharifi et al. (2013) reported that the increase in plasma HDL levels may be due to the inhibition of the active enzyme hepatic 3-hydroxy-3methylglutaryl-coenzyme A (HMG-COA). Indeed, it is suggested that medicinal plants cause a decrease in HMG-COA enzyme synthesis, which is the key enzyme in cholesterol synthesis in the liver (Yu et al., 1998). Rezaei et al. (2014) reported that Thymus vulgaris L. and Glycyrrhiza glabra or a mixture thereof in broiler diets reduced the triglyceride levels in the blood. They also found that glucose levels were lower in Glycyrrhiza glabra supplemented groups.

It was determined that the egg yolk cholesterol level decreased with the addition of licorice root $(p=0.005)$ as a result of the analyzed egg samples collected in the 4th and 8th weeks of the experiment. In the 4th and 8th weeks of the experiment, the control group had the highest egg yolk cholesterol content while the lowest egg yolk cholesterol level was determined in the $1.0 \%$ supplemented group. Awadein et al. (2010) investigated the effect of phytoestrogen source before pre-sexual maturity on performance of laying hens and indicated that egg cholesterol levels were significantly lower in $0.1 \%$ and $0.5 \%$ licorice supplemented groups than in the control group.

Table 3 - The effects of licorice root supplement on plasma biochemical parameters*

\begin{tabular}{|c|c|c|c|c|c|}
\hline \multirow{2}{*}{ Parameters } & \multicolumn{4}{|c|}{ Licorice Root Supplementation, (\%) } & \multirow{2}{*}{$p$} \\
\hline & 0 & 0.5 & 1.0 & 2.0 & \\
\hline Cholesterol (mg/dl) & $92.00 \pm 6.667$ & $86.56 \pm 8.956$ & $89.43 \pm 2.677$ & $86.35 \pm 2.871$ & 0.892 \\
\hline Triglyceride (mg/dl) & $398.12 \pm 21.203$ & $376.17 \pm 23.797$ & $394.22 \pm 20.177$ & $373.14 \pm 17.891$ & 0.780 \\
\hline LDL(mg/dl) & $118.17 \pm 5.290^{\mathrm{a}}$ & $100.36 \pm 4.095^{b}$ & $101.82 \pm 6.676^{\mathrm{ab}}$ & $114.23 \pm 4.703^{\mathrm{ab}}$ & 0.071 \\
\hline $\mathrm{HDL}(\mathrm{mg} / \mathrm{dl})$ & $25.40 \pm 2.731^{b}$ & $34.80 \pm 1.624^{a}$ & $35.20 \pm 1.529^{a}$ & $41.40 \pm 2.502^{\mathrm{a}}$ & 0.001 \\
\hline Glucose (mg/dl) & $132.00 \pm 3.674^{c}$ & $191.60 \pm 8.096^{a b}$ & $181.60 \pm 8.823^{b}$ & $205.60 \pm 6.345^{a}$ & 0.000 \\
\hline Egg yolk cholesterol 4. week (mg/g) & $21.90 \pm 1.253^{a}$ & $17.17 \pm 1.480^{b}$ & $15.00 \pm 0.855^{b}$ & $17.52 \pm 1.561^{b}$ & 0.009 \\
\hline Egg yolk cholesterol 8. week (mg/g) & $24.78 \pm 1.939^{a}$ & $19.31 \pm 1.436^{b}$ & $15.68 \pm 0.961^{b}$ & $18.12 \pm 1.657^{b}$ & 0.005 \\
\hline
\end{tabular}

*The difference between the averages shown in different letters on the same line is significant $(p<0.05)$. 
Examined in Table 4, it was determined that the oxidant capacity was the best for the use of $0.5 \%$ level of the root and that the effect of increasing levels was not significant $(p=0.001)$. Total antioxidant capacity was increased with the addition of licorice root, and it was determined as $0.893,1.113,1.239$ and 1.107 $\mu \mathrm{mol} / \mathrm{L}$ in the groups containing $0,0.5,1.0$ and $2.0 \%$ licorice root, respectively $(p=0.010)$.

The results found in the present studies smoothly correlate with earlier findings and it depicts that the licorice root has antioxidant capacity (Visavadiya \& Narasimhacharya, 2006; Sen et al., 2011; Zhao et al., 2011; Habibi et al., 2014).
Habibi et al. (2014) reported that the addition of 0 , 7.5 and $15 \mathrm{~g} / \mathrm{kg}$ of licorice root increased the antioxidant enzyme activity and lowered the MDA level in which they investigated the effect on antioxidant capacity in broiler chickens. Visavadiya \& Narasimhacharya (2006) reported that Glycyrrhiza glabra root increased hepatic HMG-CoA reductase activity in rats supplemented with 5 and $10 \mathrm{gm} \%$ levels of Glycyrrhiza glabra root in their diets and increased lipid peroxidation by increasing superoxide dismutase (SOD) and catalase enzyme activity. Sen et al. (2011) stated that glycyrrhizin, one of the important compounds of the licorice root, brought to normal levels oxidative stress parameters

Table 4 - The effects of licorice root supplement on plasma total oxidant and antioxidant capacity in laying hens. *

\begin{tabular}{|c|c|c|c|c|c|}
\hline \multirow{2}{*}{ Parameters } & \multicolumn{4}{|c|}{ Licorice Root Supplementation, (\%) } & \multirow{2}{*}{$p$} \\
\hline & 0 & 0.5 & 1.0 & 2.0 & \\
\hline Total Oxidant Status ( $\mu \mathrm{mol} / \mathrm{L})$ & $0.531 \pm 0.041^{b}$ & $0.377 \pm 0.041^{c}$ & $0.629 \pm 0.383^{\mathrm{ab}}$ & $0.671 \pm 0.041^{a}$ & 0.001 \\
\hline Total Antioxidant Status(mmol/L) & $0.893 \pm 0.031^{b}$ & $1.113 \pm 0.049^{a}$ & $1.239 \pm 0.086^{\mathrm{a}}$ & $1.107 \pm 0.048^{\mathrm{a}}$ & 0.010 \\
\hline Oxidative Stress Index & $0.059 \pm 0.004^{a}$ & $0.034 \pm 0.004^{b}$ & $0.051 \pm 0.002^{a}$ & $0.061 \pm 0.005^{a}$ & 0.002 \\
\hline
\end{tabular}

*The difference between the averages shown in different letters on the same line is significant $(p<0.05)$.

such as SOD, catalase and malondialdehyde (MDA) in diabetic mice. Zhao et al. (2011) found that 0, 5, 10, 15 and $20 \mathrm{~g} / \mathrm{kg}$ ginger root supplemented to layer diet increased plasma and egg antioxidant content.

From the above mentioned findings of the current study, it was noted that the licorice root could be used in laying hens diets to lower the egg cholesterol content without negative effect on performance. In addition, the licorice root had a positive effect on plasma cholesterol, triglyceride, LDL, HDL levels in laying hens. The antioxidant capacity in laying hens could be increased by licorice root supplement. In this context, it has been concluded that the licorice root could have a potential role to promote the production of functional eggs from healthy hens.

\section{ACKNOWLEDGEMENTS}

This study was supported by the Scientific Research Project Unit of Çukurova University, Turkey (Project number FBA-2015-4004).

\section{REFERENCES}

Al-Daraji HJ. The use of licorice extract for alleviate the adverse effects of heat stress on physiological performance of broiler chickens. International Journal of Pharmaceutical and Phytopharmacological Research 2012a;2(2):79-82.

Al - Daraji HJ. Effect of liquorice extract supplemented diet on aflatoxin degradation and blood parameters in broiler chickens. International Journal of Pharmaceutical and Phytopharmacological Research 2012b;2(2):87-91.
Aly AM, Al-Alousi L, Salem HA. Licorice: A possible anti-inflammatory and antiulcer drug. American Association of Pharmaceutical Scientists 2005;6:E74-82

Amen MHM, Muhammad SS. Effect of dietary licorice extract on some physiological and productive traits of Ross 708 broiler chicken. International Journal of Current Research 2016:8(8):36116-36121.

Asl MN, Hosseinzadeh $\mathrm{H}$. Review of pharmacological effects of Glycyrrhiza sp. and its bioactive compounds. Phytotherapy Research 2008;22:70924.

Awadein NB, Eid YZ, Abd El-Ghany FA. Effect of dietary supplementation with phytoestrogens sources before sexual maturity on productive performance of mandarah hens. Egyptian Poultry Science 2010;30(3):829-846.

Boehringer Manheim GmbH Biochemica. Methods of biochemical analysis and food analysis. Mannheim: Boehringer; 1989. p.26-28.

Boselli E, Velazco V, Caboni MF, Lercker G. Pressurized liquid extraction of lipids for the determination of oxysterols in egg contained food. Journal of Chromatography A2001;917: 239-244.

Dogan Y. Effects of licorice root onoxidative-antioxidative system [thesis] Şanlıurfa (TUR): Harran University Health Sciences Institute; 2004. p:80.

Fiore $C$, Eisenhut M, Krausse R, Ragazzi E, Pellati D, Armanini D, et al. Antiviral effects of glycyrrhiza species. Phytotherapy Research 2008;22:141-148

Fuhrman B, Volkova N, Kaplan M, Presser D, Atttias J, Hayek T, et al. Antiatherosclerotic effects of licorice extract supplementation on patients: Increased resistance of LDL to atherogenic modifications, reduced plasma lipid levels, and decreased systolic blood pressure. Nutrition 2002;18(3):268-273.

Habibi R, Sadeghi GH, Karimi A. Effect of different concentrations of ginger root powder and its essential oil on growth performance, plasma metabolites and antioxidant status in broiler chicks under heat stress. British Poultry Science 2014;55(2):228-237

Ju HS. Effects of Glycyrrhiza flavonoids on lipid peroxidation and active oxygen radicals. Acta Pharmaceutica Sinica 1989;24(11):807-812. 
Canogullari Dogan S, Baylan M, Erdoğan Z, Küçükgül A, Bulancak A
The Effects of Licorice (Glycyrrhriza glabra) Root

on Performance, Some Serum Parameters and Antioxidant Capacity of Laying Hens
Karami Z, Mirzaei H, Emam-Djomeh Z, Sadeghi Mahoonak AR, Khomeiri M. Effect of harvest time on antioxidant activity of Glycyrrhiza glabraroot extract and evaluation of its antibacterial activity. International Food Research Journal 2013;20(5):2951-2957.

Kohlert C, Van Rensen I, Marz R, Schindler G, Graefe EU, Veit M. Bioavailability and pharmacokinetics of natural volatile terpenes in animals and humans. Planta Medica 2000;66:495-505.

Kosecik M, Erel O, Sevinc E, Selek S. Increased oxidative stress in children exposed to passive smoking. International Journal of Cardiology 2005; 100:61-64.

Moradi N, Ghazi S, Amjadian T, Khamisabadi H, Habibian M. Performance and some immunological parameter responses of broiler chickens to licorice (Glycyrrhiza glabra) extract administration in the drinking water. Annual Research \& Review in Biology 2014;4(4):675-683.

Nakagawa K, Kishida H, Arai N, Nishiyama T. Mae T. Licorice flavonoids suppress abdominal fat accumulation and increase in blood glucose level in obese diabetic KK-A(y) mice. Biological and Pharmaceutical Bulletin 2004;27: 1775-1778.

Nitalikar MM, Munde KC, Dhore BV, Shikalgar SN. Studies of antibacterial activities of Glycyrrhiza glabraroot extract. International Journal of Pharm Tech Research 2010;2(1):899-901.

Rezaei M, Kalantar Nasr J. Thymus vulgaris L., Glycyrrhiza glabra, and combo enzyme in corn or barley-basal diets in broiler chickens. International Journal of Plant, Animal and Environmental Sciences 2014;4(3):418423.

Safari A, Zahedi A. The effect of different levels supplementation of Glycyrrhiza glabraextract on growth performance in male quail. International Journal of Advanced Biological and Biomedical Research 2016;4(2):214-219.

Salary J, Kalantar M, Sahebi ala MK. Ranjbar K, Hemati Matin HR. Drinking water supplementation of licorice and aloe vera extracts in broiler chickens. Scientific Journal of Animal Science 2014;3(2):41-48.

Sedghi M, Golian A, Kermanshahi H, Ahmadi H. Effect of dietary supplementation of licorice extract and a prebiotic on performance and blood metabolites of broilers. South African Journal of Animal Science 2010;40(4):371-380.

Sen S, Royt M, Chakraborti AS. Ameliorative effects of glycyrrhizin on streptozotocin-induced diabetes in rats. Journal of Pharmacy and Pharmacology 2011;63:287-296.
Sharifi SD, Saeedeh H, Khorsandi A, Khadem A, Salehi A, Moslehi HR. The effect of four medicinal plants on the performance, blood biochemical traits and ileal microflora of broiler chicks. Veterinarskiarhiv 2013;83(1):69-80.

Shibata S. A drug over the millennia: Pharmacognosy, chemistry and pharmacology of licorice. Yakugakuzasshi 2000;120(10):849-862.

SPSS. Released 2018. PASW statistics for windows. Version 18.0. Chicago: SPSS; 2018

Tan G, Zhu Z, Zhang H, Zhao L, Liu Y, Dong X, et al. Analysis of phenolic and triterpenoid compounds in licorice and rat plasma by highperformance liquid chromatography diode-array detection, time-offlight mass spectrometry and quadrupole ion trap mass spectrometry. Rapid Communications in Mass Spectrometry 2010;24:209-218.

Tominaga Y, Tatsumasa M, Mitsuaki K, Yoshiro S, Hideyuki I, Nakagawa N Licorice flavonoid oil effect body weight loss by reduction of body fat mass in overweight subject. Journal of Health Sciences 2006;52:672683.

Utsunomiya T, Kobayashi M, Pollard RB, Suzuki F. Glycyrrhizin, an active component of licorice roots, reduces morbidity and mortality of mice infected with lethal doses of influenza virus. Antimicrobial Agents and Chemotherapy 1997;41(3):551-556.

Vaya J, Belinky PA Aviram M. Antioxidant constituents from licorice roots isolation, structure elucidation and antioxidative capacity toward LDL oxidation. Free Radical Biology and Medicine 1997;23:302-313.

Visavadiya NP, Narasimhacharya AVRL. Hypocholesterolaemic and antioxidant effects of Glycyrrhiza glabra (Linn) in rats. Molecular Nutrition \& Food Research 2006;50:1080-1086.

Yokota T, Nishio H, KubotaY, Mizoguchi M. The inhibitory effect of glabridin from licorice extracts on melanogenesis and inflammation. Pigment Cell Research 1998;11:355-361.

Yu SG, Hsu JC, Chiou PWS. Effects of $\beta$-glucanase supplementation of barley diets on growth performance of broilers. Animal Feed Science and Technology 1998;70:353-361.

Zhao X, Yang B, Yang WR, Wang Y, Jiang SZ, Zhang, GG. Effects of ginger root (Zingiberofficinale) on laying performance and antioxidant status of laying hens and on dietary oxidation stability. Poultry Science 2011;90:1720-1727. 
